\title{
USO DO QUIABO (ABELMOSCHUS ESCULENTUS) COMO FLOCULANTE NA DESESTABILIZAÇÃO DE EMULSÕES ÓLEO/ÁGUA
}

E. M. S. SILVA', A. C. SILVA', A. S. RIBEIRO ${ }^{3}$ e S. H. CRUZ ${ }^{4}$

${ }^{1}$ Universidade Federal de Goiás. andrecarlos@catalao.ufg.br

${ }^{2}$ Universidade Federal de Goiás. elenice@catalao.ufg.br

${ }^{3}$ Bolsista PIVIC graduando em Engenharia de Minas, Campus Catalão, UFG. andrer8@gmail.com

${ }^{4}$ Bolsista PIVIC graduando em Engenharia de Minas, Campus Catalão, UFG. santiago-eng@hotmail.com.br

Artigo submetido em novembro/2013 e aceito em julho/2014

DOI: http://dx.doi.org/10.15628/holos.2014.1774

\section{RESUMO}

O presente artigo visa apresentar os resultados da utilização do quiabo (Abelmoschus Esculentos) como floculante no processo de desestabilização de emulsões do tipo óleo em água, sendo estas emulsões produzidas industrialmente no setor mineiro-metalúrgico. Vários problemas ambientais podem ser gerados por emulsões óleo em água, uma vez que este tipo de emulsão reduz a oxigenação dos corpos d'água, acarretando, assim, um intenso desequilíbrio ambiental. Utilizando-se quiabos que seriam posteriormente descartados por não apresentarem mais utilidade à alimentação humana buscou-se, além do desenvolvimento da tecnologia com o uso deste reagente. A potencialidade do uso do quiabo como floculante foi confirmada através dos ensaios experimentais realizados.

PALAVRAS-CHAVE: Emulsões; Floculação; Quiabo.

\section{USE OF OKRA (ABELMOSCHUS ESCULENTUS) AS A FLOCCULANT IN DESTABILIZING OIL / WATER EMULSIONS}

\begin{abstract}
This paper presents the results of the use of okra (Abelmoschus Esculentos) as a flocculant in the process of destabilization of emulsions of oil in water, and these emulsions produced industrially in mining and metallurgy. Various environmental problems might be generated by oil in water emulsions, since this type of emulsion decreases the oxygenation of water bodies,
\end{abstract}

causing thus a strong environmental imbalance. Using okra that would eventually be discarded for not presenting more useful for human looked up, and the development of technology with the use of this reagent. The potential use of okra as flocculant was confirmed through experimental tests performed.

KEYWORDS: Emulsions; Flocculation; Okra. 


\section{INTRODUÇÃO}

Segundo a Organização dos Estados Americanos (OEA) as indústrias que mais contaminam o meio ambiente são as dos setores mineiro e metalúrgico, lançando diariamente no meio ambiente grandes volumes de gases, resíduos aquosos e/ou sólidos, contendo elementos de toxicidade variada.

O petróleo e seus derivados estão entre os principais poluentes que podem causar degradação ao meio ambiente, pois quando em contato com a água, geram as emulsões. Esses contaminantes, quando presentes na água, são de difícil remoção, mesmo em pequenas quantidades, afetam os processos fotossintéticos e as trocas gasosas causando a morte de animais e plantas. Além disso, esses poluentes são estáveis à luz, ao calor e de difícil biodegradação.

Estima-se que um litro de óleo contamine aproximadamente um milhão de litros de água limpa. Este poluente, quando em presença de um saponáceo, se emulsiona. A emulsão gerada é estável à luz e ao calor e de difícil biodegradação, acarretando assim, efeitos prejudiciais a todo o ecossistema impactado.

Um dos processos utilizados visando à desestabilização de emulsões é a coagulação química. Segundo Pavanello (2001), a coagulação corresponde à desestabilização da dispersão coloidal obtida por redução das forças de repulsão entre as partículas com cargas elétricas por meio da adição de um composto químico apropriado (por exemplo, sais de ferro ou de alumínio) ou de polímeros sintéticos, seguidos por agitação rápida, com o intuito de homogeneizar a mistura. De acordo com Silva (2008) o objetivo da coagulação é reduzir o potencial zeta das partículas de forma que as forças repulsivas entre as partículas sejam menores que as forças atrativas de van der Waals, provocando a assim a desestabilização da emulsão.

Segundo Lima (2007), o uso do quiabo no tratamento de água e esgoto como coadjuvante da coagulação química tem apelo compatível com o ambiente, especialmente quando associado ao uso de material renovável, ao baixo potencial de toxidez e ao potencial de sustentabilidade da agricultura familiar. O polímero natural tem menor custo, sendo que muitos destes produtos naturais fazem parte da alimentação humana em vários continentes, portanto não apresenta risco de danos à saúde humana a longo prazo, conforme existe suspeita com relação aos monômeros de acrilamida. O desenvolvimento de reagentes naturais apresenta elevada relevância para a atividade industrial e a sociedade como um todo, uma vez que estes são biodegradáveis ao contrário dos reagentes sintéticos utilizados na indústria.

O presente trabalho visou determinar as corretas dosagens de ácido oleico, detergente doméstico líquido neutro e água para a síntese de emulsões estáveis e posteriormente buscou-se identificar a influência da dosagem do quiabo e o tempo de repouso necessário na desestabilização da emulsão, medida pela variação da turbidez da mesma. O quiabo apresentou resultados que sugerem a sua potencialidade na desestabilização de emulsões óleo/água. 


\section{METODOLOGIA}

\subsection{Sínteses das emulsões do tipo óleo em água}

A turbidez pode ser definida como sendo o grau de redução que a luz sofre ao atravessar certa quantidade de uma dada solução, devido às partículas e substâncias presentes na mesma. Como as dispersões coloidais são frequentemente identificadas pela sua turbidez utilizou-se a medição da turbidez das emulsões como parâmetro de aferição da estabilidade das emulsões sintetizadas. Para tal foi utilizado um turbidímetro portátil da Hanna modelo HI 93703C, com faixa de leitura de 0 a 1.000 NTU.

Foram realizados ensaios variando as dosagens de ácido oleico e de detergente de modo a sintetizar emulsões estáveis com turbidez na faixa de 900 a 1.000 NTU. A limitação desta faixa de turbidez deve-se ao fato do equipamento utilizado para a mediação da turbidez ter faixa de trabalho de 0 a 1.000 NTU. Para cada dosagem utilizada, foram sintetizadas três emulsões de modo a verificar a reprodutibilidade da mesma. Inicialmente, para a síntese da emulsão, preparou-se uma emulsão concentrada constituída por detergente, ácido oleico e água destilada, nas seguintes dosagens:

- Tipo A: $1 \mathrm{ml}$ de ácido oleico e $1 \mathrm{ml}$ de detergente, diluídos em $98 \mathrm{ml}$ de água destilada;

- Tipo B: $2 \mathrm{ml}$ de ácido oleico e $2 \mathrm{ml}$ de detergente, diluídos em $96 \mathrm{ml}$ de água destilada;

- Tipo C: $3 \mathrm{ml}$ de ácido oleico e $3 \mathrm{ml}$ de detergente, diluídos em $94 \mathrm{ml}$ de água destilada;

- Tipo D: $1 \mathrm{ml}$ de ácido oleico e $2 \mathrm{ml}$ de detergente, diluídos em $97 \mathrm{ml}$ de água destilada;

- Tipo E: $1 \mathrm{ml}$ de ácido oleico e $0 \mathrm{ml}$ de detergente, diluídos em $99 \mathrm{ml}$ de água destilada;

- Tipo F: $0 \mathrm{ml}$ de ácido oleico e $1 \mathrm{ml}$ de detergente, diluídos em $99 \mathrm{ml}$ de água destilada.

Após a síntese as emulsões concentradas foram agitadas mecanicamente por 5 minutos a 2.000 rpm de modo a promover a homogeneização das mesmas. Em seguida as emulsões concentradas foram diluídas em $510 \mathrm{ml}$ de água destilada e novamente agitadas por 5 minutos a $2.000 \mathrm{rpm}$, produzindo $610 \mathrm{ml}$ de emulsão estável. De modo a verificar a estabilidade da emulsão sintetizada amostras de $10 \mathrm{ml}$ foram coletadas e armazenadas em cubetas para a medição periódica de sua turbidez. Os intervalos de tempo adotados entre as leituras da turbidez foram: 0, $15,30,60,120$ e 1440 minutos (24 horas). A figura 1 apresenta uma amostra de uma emulsão do tipo $D$, coletada para medição da turbidez da emulsão sintetizada. A figura 2 apresenta a variação da turbidez das emulsões com o passar do tempo para os seis tipos de emulsões testados. A emulsão tipo A (curva em azul) era composta por $1 \mathrm{ml}$ de ácido oleico e $1 \mathrm{ml}$ de detergente, diluídos em $98 \mathrm{ml}$ de água destilada; a emulsão tipo B (reta horizontal em vermelho) por $2 \mathrm{ml}$ de ácido oleico e $2 \mathrm{ml}$ de detergente, diluídos em $96 \mathrm{ml}$ de água destilada; a emulsão tipo C (reta horizontal em verde) por $3 \mathrm{ml}$ de ácido oleico e $3 \mathrm{ml}$ de detergente, diluídos em $94 \mathrm{ml}$ de água destilada; a emulsão tipo $D$ (curva em lilás) por $1 \mathrm{ml}$ de ácido oleico e $2 \mathrm{ml}$ de detergente, diluídos em $97 \mathrm{ml}$ de água destilada; a emulsão tipo $\mathrm{E}$ (reta horizontal em azul claro) por $1 \mathrm{ml}$ de ácido oleico e $0 \mathrm{ml}$ de 
detergente, diluídos em $99 \mathrm{ml}$ de água destilada e a emulsão tipo $\mathrm{F}$ (reta horizontal em laranja) por $0 \mathrm{ml}$ de ácido oleico e $1 \mathrm{ml}$ de detergente, diluídos em $99 \mathrm{ml}$ de água destilada.

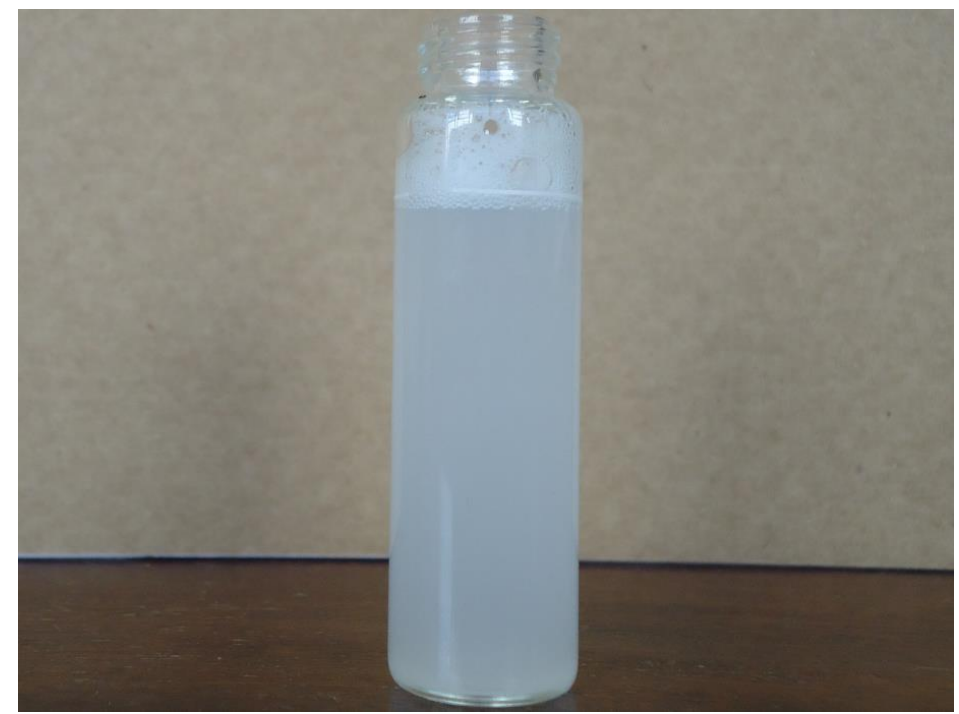

Figura 1 - Cubeta de $10 \mathrm{ml}$ contendo amostra da emulsão do tipo D.

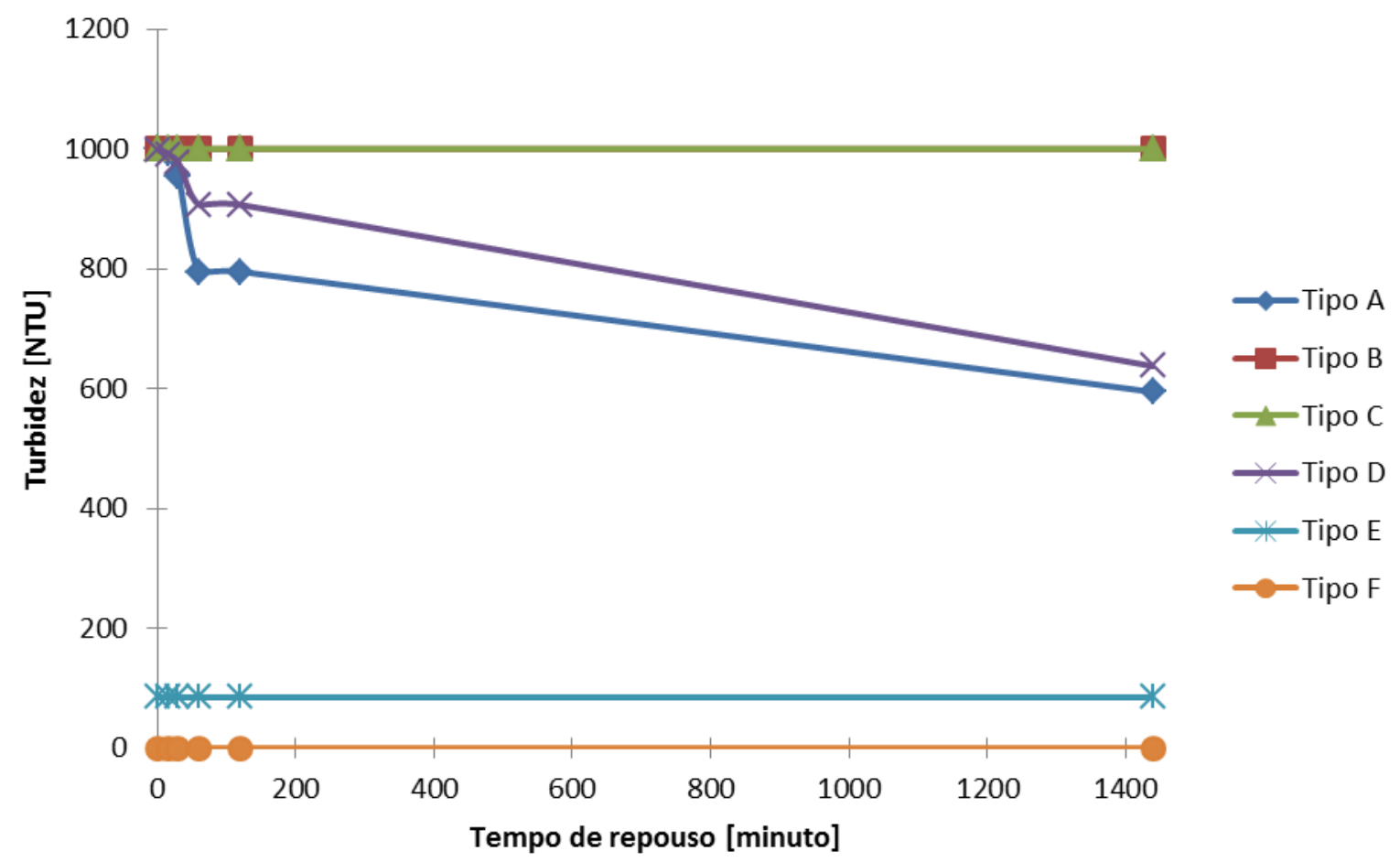

Figura 2 - Variação da turbidez [NTU] em relação ao tempo de repouso [min].

Dentre as dosagens de reagentes testadas aquela que apresentou uma turbidez inicial dentro da faixa estabelecida (entre 900 e 1000 NTU) e que se manteve relativamente estável 24 horas após sua síntese foi a emulsão tipo $D$, composta por $1 \mathrm{ml}$ de ácido oleico e $2 \mathrm{ml}$ de 
detergente, diluídos em $97 \mathrm{ml}$ de água destilada. Portanto esta foi à composição considerada ideal para ser aplicado o ensaio de desestabilização utilizando o pó de quiabo.

\subsection{Preparo do quiabo para uso como floculante}

A preparação da mucilagem de quiabo utilizada como floculante natural envolveu a

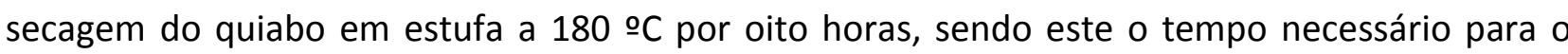
quiabo reduzir aproximadamente $94 \%$ de seu peso (Silva et ali, 2011), pulverização em pilão de aço inoxidável e peneiramento do produto obtido em uma peneira com abertura de $0,25 \mathrm{~mm}$ (60\# série Tyler). 0 material passante nesta peneira é a mucilagem de quiabo pronta para o uso como floculante natural. A figura 3 apresenta uma amostra de quiabo após a secagem na estufa e a figura 4 a mucilagem de quiabo após pulverização e peneiramento, pronta para ser utilizada como floculante natural.

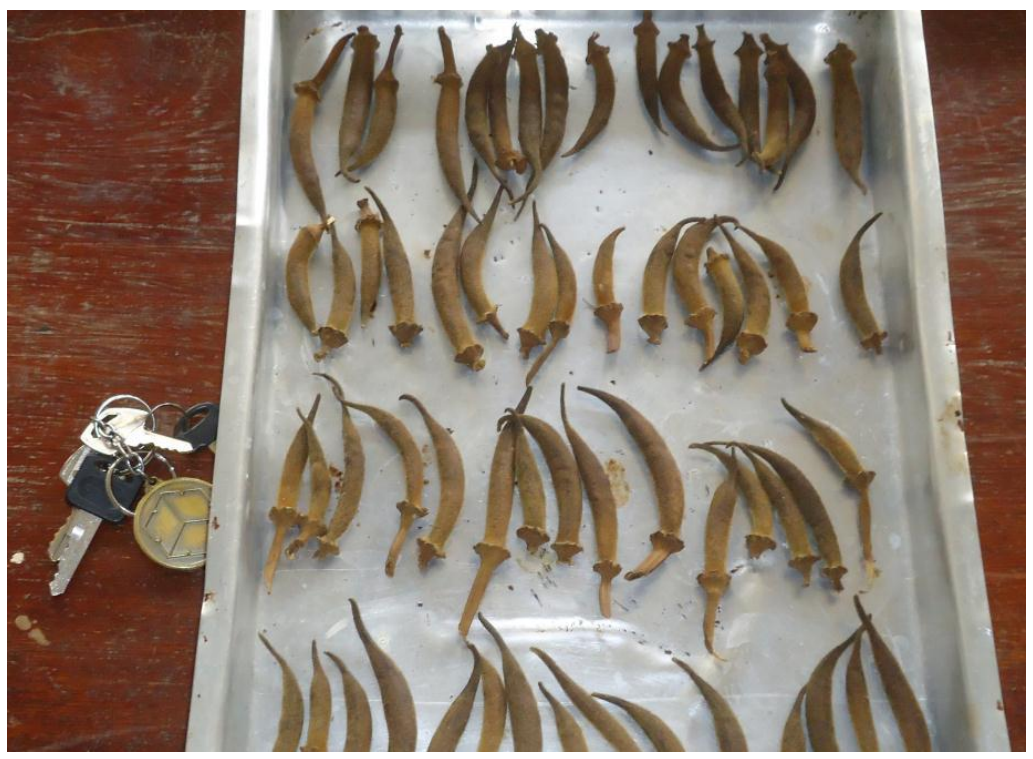

Figura 3 - Quiabos após 8 horas de desidratação em estufa a $180^{\circ} \mathrm{C}$.

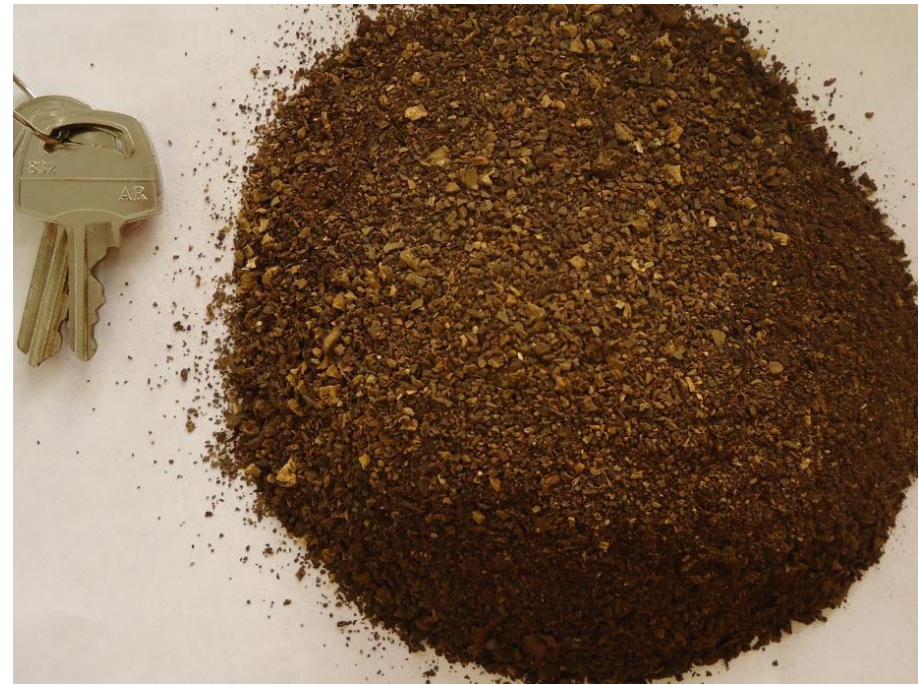

Figura 1 - Mucilagem de quiabo pronta para utilização. 


\subsection{Ensaios de desestabilização}

Os ensaios de desestabilização das emulsões foram realizados em batelada, seis ensaios de cada vez, à temperatura ambiente (aproximadamente $25 \stackrel{\circ}{\circ}$ ). Alíquotas de $100 \mathrm{ml}$ da emulsão sintetizada eram colocadas em béqueres junto com a mucilagem de quiabo, sendo a mistura agitada mecanicamente durante 5 minutos, visando aumentar o contato da mucilagem de quiabo com a emulsão. Após a agitação a mistura foi deixada em repouso e a sua turbidez medida coletando-se amostras de cada béquer da seguinte forma:

1. Amostras de $10 \mathrm{ml}$ dos béqueres 1 e 2 após 10 minutos de repouso;

2. Amostras de $10 \mathrm{ml}$ dos béqueres 3 e 4 após 30 minutos de repouso;

3. Amostras de $10 \mathrm{ml}$ dos béqueres 5 e 6 após 60 minutos de repouso;

4. Amostras de $10 \mathrm{ml}$ de todos os béqueres após 120 minutos de repouso.

Foram realizados seis testes com as seguintes dosagens de mucilagem de quiabo cada: 1 , 20, 50 e $100 \mathrm{~g} / \mathrm{L}$. Contudo, apenas esta a dosagem de $100 \mathrm{~g} / \mathrm{L}$ apresentou redução significativa na turbidez da emulsão. Foram executados apenas seis testes para cada dosagem devido à baixa conversão do quiabo in natura em mucilagem de quiabo (apenas $6 \%$ em massa de mucilagem de quiabo eram obtidas ao final do processo de preparação).

\section{RESULTADOS}

A figura 5 apresenta os resultados obtidos para a desestabilização da emulsão com a adição 100 $\mathrm{g} / \mathrm{L}$ de mucilagem de quiabo. A reta horizontal em azul representa a turbidez medida para a alíquota de emulsão in natura (sem adição da mucilagem de quiabo), a curva em vermelho apresenta a média dos resultados obtidos e a curva em verde apresenta o ensaio que obteve a menor turbidez encontrada.

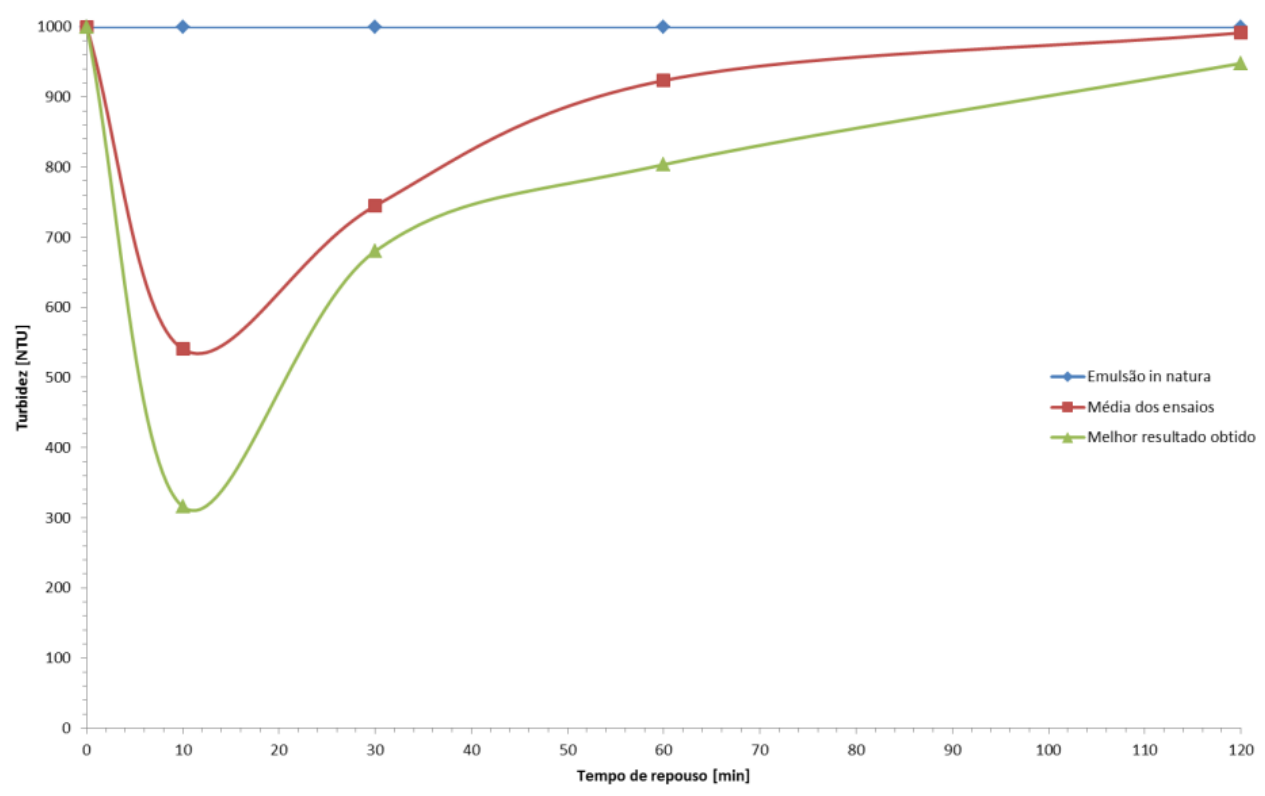

Figura 2 - Variação da turbidez [NTU] em relação ao tempo de repouso [min]. Concentração de $100 \mathrm{~g} / \mathrm{L}$ de mucilagem de quiabo. 


\section{DISCUSSÃO DOS RESULTADOS}

Dentre as dosagens de mucilagem de quiabo testada apenas a dosagem de $100 \mathrm{~g} / \mathrm{L}$ apresentou alguma mudança na turbidez da emulsão. Tal dosagem provocou uma redução temporária da turbidez da emulsão, como pode ser verificado na figura 5. Após 10 minutos de repouso a turbidez da emulsão cai de 1000 para 316 NTU, resultado este obtido para o ensaio de mais baixa turbidez após 10 minutos de repouso. No entanto, após 30 minutos de repouso observou-se a elevação da turbidez da emulsão, retornando a 1000 NTU após aproximadamente duas horas de repouso.

Uma vez sendo o sabão uma molécula anfipática capaz de ligar o óleo (apolar) a moléculas de a água (polar) supomos que a mucilagem de quiabo seja capaz de quebrar esta ligação e atuar como floculante natural, unindo as micelas de óleo presente na emulsão. Contudo o observado na figura 5 sugere um efeito apenas temporário na quebra das ligações do sistema óleo-sabão-água.

\section{CONCLUSÕES}

O presente trabalho visou o estudo da utilização do quiabo como floculante natural a ser usado na desestabilização de emulsões do tipo óleo/água. Como se trata de uma pesquisa exploratória, vários parâmetros de teste foram levantados, tais como: forma de extração do polímero, temperatura, pH, concentração do polímero extraído e composição da emulsão. Tendo em vista que o desenvolvimento da mucilagem de quiabo se deu a partir de quiabos descartados para o consumo humano devido a seu grau avançado de amadurecimento e sendo o Brasil um grande produtor desta cultura entende-se como de suma importância o desenvolvimento deste floculante natural que possa resolver ou atenuar problemas ambientais de forma sustentável e gerando avanço tecnológico para o país.

Destaca-se o fato que a mucilagem de quiabo na concentração de $100 \mathrm{~g} / \mathrm{L}$ foi capaz de diminuir a turbidez da emulsão por alguns minutos. Podem-se citar alguns pontos a serem trabalhados para a possível melhoria destes resultados, tais como: aumento da concentração da mucilagem de quiabo, a estudo de outras formas de obtenção do princípio ativo presente no quiabo e utilização de coagulantes, tais como o sulfato de alumínio, juntamente com a mucilagem de quiabo.

\section{AGRADECIMENTOS}

Os autores agradecem ao apoio financeiro, imprescindível para o desenvolvimento do presente trabalho, das agências brasileiras de fomento à pesquisa CNPq, CAPES, FAPEG e FUNAPE e à Universidade Federal de Goiás, pelo apoio dado ao mesmo.

\section{REFERÊNCIAS}

1. AGARWAL, M., SRINIVASAN, R., MISHRA, A. Study on Flocculation Efficiency of Okra Gum in Sewage Waste Water. Macromol. Mater. Eng. 2001, 286, No. 9 560-563.

2. LIMA, G. J. A. Uso de polímero natural do quiabo como auxiliar de floculação e filtração em 
tratamento de água e esgoto. Dissertação de mestrado em engenharia ambiental, UERJ, Rio de Janeiro/RJ, 154 p, 2007.

3. MARTINEZ, M. Quiabo. Disponível em: http://www.infoescola.com/plantas/quiabo. Acesso em: 27 de jun. 2012.

4. SILVA, E. M. S., SILVA, A. C., ASSIS, G. B. R. Ensaio de desidratação do quiabo (Abelmoschus Esculentus) para uso como floculante. 63a Reunião Anual da Sociedade Brasileira para o Progresso da Ciência. Goiânia, v. 1, p. 1-4, 2011.

5. LUZ, A. B. DA; SAMPAIO, J. A.; ALMEIDA, S. L. M. DE. Tratamento de Minérios. 4a Ed. CETEM, Rio de Janeiro/RJ, 2004.

6. MANIASSO, N. Ambientes micelares em química analítica. Química Nova, v. 24, n. 1, p. 87-93, 2001.

7. MYERS, D. Surfaces, Interfaces and Colloids. 2nd ed. Hardcover, 1999.

8. PAVANELLI, G. Eficiência de diferentes tipos de coagulantes na coagulação, floculação e sedimentação de água com cor ou turbidez elevada. Dissertação de mestrado, USP, São Carlos, 233p, 2001.

9. RODRIGUES, R. T.; RUBIO, J. Inovação tecnológica no tratamento de águas oleosas de plataformas marítimas. XIX Prêmio Jovem Cientista, Água - Fonte de Vida, 2003.

10. SHAW, D. J. Introdução à química dos coloides e de superfícies. Ed. Edgard Blücher Ltda, São Paulo, 1975.

11. SILVA, E. M. S. Desestabilização de emulsões visando a redução do teor de óleo em água. Dissertação de mestrado em engenharia mineral, UFOP, Ouro Preto/MG, 168p, 2008. 